\title{
Environmental Issues and Disaster Management
}

\author{
S Jeevananda Reddy* \\ Formerly Chief Technical Advisor, Telangana Academy of Sciences Convener, Forum for a Sustainable Environment, India
}

Received: 瞽 September 26, 2018; Published: 制 October 01, 2018

*Corresponding author: S Jeevananda Reddy, Formerly Chief Technical Advisor WMO/UN and Expert FAO/UN, Telangana Academy of Sciences Convener, Forum for a Sustainable Environment, India

\section{What is Environment and Why it is Important?}

This is a vast subject encompassing the entire system of human activities. Simply, environment is defined as: all forms that surrounds us life forms [humans, animals, birds] \& non-life forms moving [air, water] \& non-moving [mountains, forests]. Human settlement interacts with the environment in a complex fashion involving many different scales. The survival of all life forms on the Earth is a function of healthy and balanced growth of environment in space and time. The new economic order must make it mandatory to protect the environment to have a balanced growth at present and in future. We should not think forests, trees, and croplands as carbon sinks, but we must look at them that provide clean air for our survival. We take oxygen from the surroundings and give out carbon dioxide; and at the same time plants take carbon dioxide and release oxygen. These two groups of ecosystems complement each other. Drastic changes in either of them leads to unsustainable environment. Today, population is the greatest problem facing the country. In the past, the nature used to keep the balance through natural disasters and epidemics. Now, with the advent of modern medicine we are in control of epidemics and with the advancements in science and technology we are in a position to reduce the impacts of natural disasters but at the same time increased the diseases and disease rate. Human societies' impact on environment is a function of population growth, more particularly in urban areas with around $30 \%$ concentration which may reach $60 \%$ by 2050 , their consumption pattern and their innovative technologies-based lifestyles. We consume resources from healthy ecosystems and make it unhealthy ecosystem over time.

Just before Paris Climate meet in 2015, Pope Francis released a provocative encyclical on the environment-Laudato Si. Again, later he emphasized that destroying the environment was a sin. He further noted that humans were turning the planet into wasteland of debris, desolation and filth, and called for urgent action. Pope Francis further emphasized that, "We must not be indifferent to the loss of biodiversity and destruction of ecosystems, often caused by our irresponsible and selfish behavior". He called for consumers to modify their modern lifestyles by reducing waste, planting trees, etc. The same was emphasized by UN \& US President just before Paris meet. But this was not reflected in the Paris Agreement Document. A report of UNDP [United Nations Environment Program] warns about the rising water pollution in three continents, namely Asia, Africa and Latin America, placing hundreds of millions of people at risk of contracting life-threatening diseases and putting aquatic flora and fauna under extinction threat. It observed that, "The increasing amount of wastewater being dumped into our surface waters is deeply troubling.

\section{What is Disaster and how it Impacts Environment?}

The major causes for unsustainable environmental growth in the modern world are the "disasters". A disaster is a serious disruption of the functioning of a community or a society involving widespread human, material, economic or environmental loss and impacts, which exceeds the ability of the affected community or society to cope using its own resources. We are encountering with three types of hazards, namely natural, manmade and socio-natural hazards. The natural disasters are beyond human control and thus we need to adapt to them. The manmade disasters are though in the hands of man they rarely follow the precautionary principle prevention is better than cure policy. Here human greed and poor governance play the pivotal role along with poor civic sense among poor to elite.

\section{Natural hazards}

Are hazards which are caused because of natural phenomena. They are of meteorological, geological or even biological origin. Examples of natural hazards are cyclones, tsunamis, earthquakes and volcanic eruptions which are exclusively of natural origin.

\section{Manmade hazards}

Are hazards which are due to human negligence. Manmade hazards are associated with industries or energy generation facilities and include explosions, leakage of toxic waste, pollution, 
dam failure, wars or civil strife, etc. Now a day modern festival also comes under this group. The list of hazards is very long. Many occur frequently while others take place occasionally.

\section{Socio-natural hazards}

Landslides, floods, drought, fires are socio-natural hazards since their causes are both natural and manmade. For example, flooding may be caused because of heavy rains, landslide or blocking of drains with human waste are human induced. However, the rapid growth of the world's population and its increased concentration often in hazardous environments has escalated both the frequency and severity of disasters. With the tropical climate and unstable land forms, coupled with deforestation, unplanned growth proliferation, non-engineered constructions which make the disaster-prone areas more vulnerable, tardy communication, and poor or no budgetary allocation for disaster prevention, developing countries suffer more or less chronically from natural disasters. Asia tops the list of casualties caused by natural hazards.

\section{Nature}

Is being destroyed by both natural disasters such as cyclonic activity, earthquakes, volcanic activity, tsunamis, etc.; and activities to meet human greed such as wars, oil-gas-water extraction, physical destruction of ecologically sensitive zones and destruction of natural water flow systems, violation of acts or laws, etc. are often attributed to global warming. The flood disasters in Hyderabad in September 2000; Uttarakhand in June 2013; Jammu and Kashmir/ Srinagar in September 2014; November-December 2015 in Chennai \& Nellore; August 2018 in Mumbai; etc. are the manifestations of human greed. Now governments are wrongly putting the blame on global warming. Indian Institutions are making even Prime Minister to make false statements like "Chennai floods are associated with the Global Warming". We must realize the fact that "ignorance is terrible, but exaggeration is dangerous". A classic example of state disaster is Kerala August 2018 floods. To tackle the problem in the right way we need the cause of the problem in the correct way. The impacts of manmade disasters have been increasing with the time.

\section{What is the Impact of Pollution on Environment?}

Access to quality water and air are essential for human health and human development. Both are at risk if we fail to stop the pollution. Stan Cox's "Sick Planet: Corporate Food and Medicine", argues that corporate food and medicine industries are destroying environments and ruining living conditions across the world. Unplanned urbanization, population explosion, agriculture and uncontrolled sewage discharge in to rivers and lakes/tanks are primary reason behind the rise in surface water pollution. We are using groundwater indiscriminately, but we are not taking any action on recharging the groundwater and thus causing water pollution. The surface polluted water also polluting groundwater. Industries, mining, transport, etc. have been the major contributors of pollution. Civilization developed on the banks of the rivers throughout the world, as water was the basic necessity for all living beings. In the last two centuries, with the industrialization primarily around urban centers the rural population started migrating to urban centers for greener pastures. All these in urban areas and modern agriculture practices in rural areas introduced the evil pollution. Thus, directly and indirectly affected the environment and living organisms on the Earth. Children and adults today carry an estimated 300 or more chemical residues that were not present in their grandparent's body. These chemicals accumulate in the body with the time and are passed on to the next generation often at high concentrations. Water borne diseases caused by intake of chemicals and contaminated water affecting around 3.4 million people globally.

We rarely look at precautionary principle; instead of prevention measures, we try controlling measures with which we rarely achieve the stated goal. Also, with isolated control measures, the scenario will not change. Take for example: will the Supreme Court order really improve the industrial pollution? The court needs to look into ground realities such as excess production and zero pollution. Without that, there will not be any improvement in reducing the pollution levels. Water is a natural resource, fundamental to life, livelihood, food security and sustainable development; it is also s scarce resource. India has more than $17.11 \%$ of the world's population but has only $4.6 \%$ of world's water resources with $2.3 \%$ of world's land area. Precipitation and snow melt provide the fresh water; though they are renewable, they are highly variable with space and time; climate change plays vital role in the year to year water availability over different parts of India. India crossed 130 crore population and wasting around $40-50 \%$ of food produced - it is around $30 \%$ for the world as reported by FAO and the resources used to produce that is also simultaneously wasted. This is basically because of unplanned agriculture driven by technology that looks at profit than over the environment. Modern agriculture is causing air, water, soil and food pollution. We look at production growth, but we rarely look at the impact on environment by such technologies, more particularly on water resources and health of life forms. Though the industry uses very little, when the pollutants generated by industries released in to potable water, it changes potable water in to polluted water. This very rarely we account as the water used by industry.

\section{How do We Achieve the Disaster Risk Reduction? \\ Preparedness}

It is a protective process that embraces measures which enable governments, communities and individuals to respond rapidly to disaster situations to cope with them effectively. It also includes the formulation of viable emergency plans, the development of warning systems, the maintenance of inventories and the training of 
personnel. It may also embrace search and rescue measures as well as evacuation plans for areas that may be at risk from a recurring disaster. Preparedness therefore encompasses those measures taken before a disaster event which are aimed at minimizing loss of life, disruption of critical services, and damage when the disaster occurs.

\section{Mitigation}

It embraces measures taken to reduce both the effect of the hazard and the vulnerable conditions to it in order to reduce the scale of a future disaster. Therefore, mitigation activities can be focused on the hazard itself or the elements exposed to the threat. Examples of mitigation measures which are hazard specific include water management in drought prone areas, relocating people away from the hazard prone areas and by strengthening structures to reduce damage when a hazard occurs. In addition to these physical measures, mitigation should also aim at reducing the economic and social vulnerabilities of potential disasters. However, with poor civic sense among poor to elite along with poor governance in some cases this is rarely achieved. Examples under this are the flood disasters mentioned earlier pages.

\section{Industrial Pollution Related Disasters}

In the case of pollution, some are point sources and some others are non-point source. Industrial pollution is point source pollution.
There are rules and regulations to control the pollution through Water Act of 1974, Air Act of 1981, and Environmental Act of 1986, EIA Notification 2006, etc.; and for which pollution control boards were established to regulate them. However, the system is weak. A classic example to this is the Bhopal gas tragedy. This disaster would have been averted if the government departments followed the stipulated norms. Instead, they allowed residential houses all around the factory, which has been resulted the great tragedy. Another example is urban water [surface \& groundwater] pollution that drastically reduced the potable water availability.

\section{Agricultural pollution related disaster}

Agricultural pollution is non-point source pollution and thus there are no rules and regulations. The only solution is change of technology. Though some farmers are attempting in this direction, the governments are not showing much interest in this direction. Gulf of Mexico turned in to a dead zone spreading over thousands of square kilometers with runoff that contains residues of chemical fertilizers \& sprays from agricultural farms carried through Mississippi River in USA.

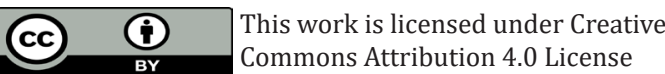

To Submit Your Article Click Here: Submit Article

DOI: 10.32474/OAJESS.2018.01.000114

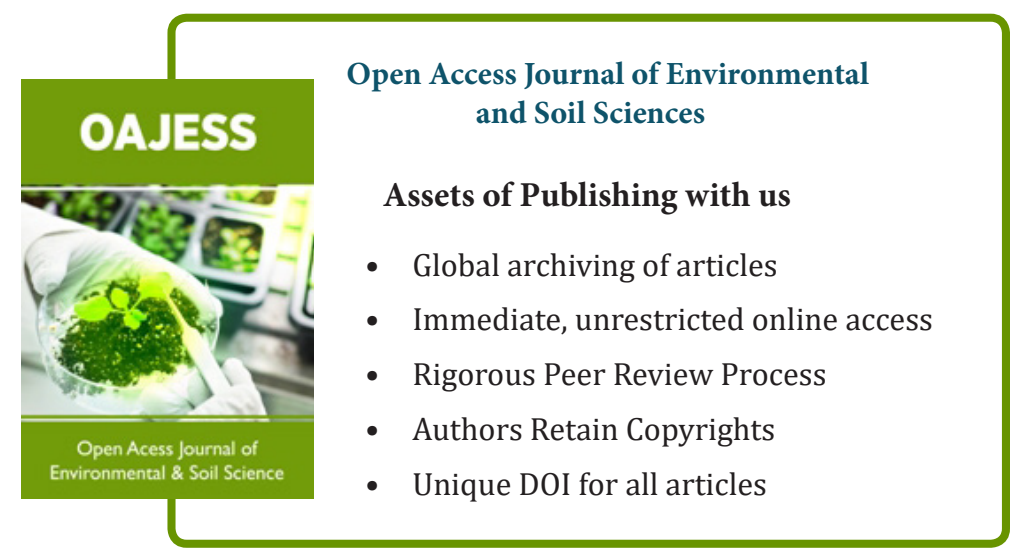

